\title{
A Análise Urbana Sob a Perspectiva de Horácio Capel
}

\section{Horácio Capel's Perspective of Urban Analysis}

\author{
Denis Rodrigues Dantas ${ }^{i}$ \\ Universidade Federal do Rio Grande do Norte \\ Natal, Brasil \\ Élida Thalita Silva de Carvalhoii \\ Universidade Federal do Rio Grande do Norte \\ Natal, Brasil \\ Julia Diniz de Oliveiraiii \\ Universidade Federal do Rio Grande do Norte \\ Natal, Brasil
}

\begin{abstract}
Resumo: O estudo da morfologia urbana possibilita interpretar a cidade a partir dos diversos elementos e dimensões que a ela estão imbricados. Nessa perspectiva, o presente artigo tem como objetivo apresentar as principais contribuições do geógrafo espanhol Horácio Capel para análise urbana na Geografia, tendo a morfologia urbana como ponto crucial da análise. Para tanto, utilizamos como aporte teórico os três volumes da sua obra La Morfologia de las Ciudades publicados originalmente em 2002, 2005 e 2013. Como resultado, o leitor encontrará uma discussão acerca da morfologia urbana e dos elementos que compõem a cidade, compreendendo como as edificações, as técnicas, a cultura e as dimensões sociais contribuem para a consolidação das formas urbanas, além de uma discussão acerca dos agentes e atores sociais que produzem e modelam o espaço urbano na contemporaneidade.
\end{abstract}

Palavras-chave: Horácio Capel; Morfologia Urbana; Agentes Urbanos.

Abstract: The study of urban morphology makes it possible to interpret cities from the various elements and dimensions that constitute them. Using this perspective, we present the main contributions of the Spanish geographer Horácio Capel for urban analysis in geography and urban morphology in particular, which are encountered in the three volumes work La morfologia de las ciudades and originally published in 2002, 2005 and

\footnotetext{
'Mestre pelo Programa de Pós-Graduação em Geografia. Graduado em Licenciatura em Geografia pela Universidade Federal de Campina Grande. denis_rdantas@hotmail.com. https://orcid. org/0000-0001-9818-5688

ii Mestra pelo Programa de Pós-Graduação em Geografia. Graduada em Bacharel em Geografia pela Universidade Federal do Rio Grande do Norte. elidathalita@hotmail.com. https://orcid.org/00000001-6068-4801

iii Doutoranda pelo Programa de Pós-Graduação em Geografia. Mestra em Geografia pela Universidade Federal do Rio Grande do Norte. Graduada em Licenciatura em Geografia pela Universidade Federal de Campina Grande. juliadiniz.oliveira@hotmail.com. https://orcid.org/0000-0002-4259-245X
} 
2013. Urban morphology and the elements that make up the city are discussed in order to understand how buildings, techniques, culture and social dimensions contribute to the consolidation of urban forms and how agents and social actors produce and model urban space today.

Keywords: Horácio Capel; Urban Morphology; Urban Agents.

\section{Introdução}

Horácio Capel Saez é professor e pesquisador de Geografia Humana na Universidade de Barcelona desde 1983. Até meados dos anos 1970, realizou pesquisas relacionadas a morfologia, sistemas urbanos e percepção do espaço, incluindo produções como: Estudios Sobre el Sistema Urbano (1974 e 1982), Capitalismo y Morfología Urbana em España (publicada em 1975, com quatro edições sequenciais, além de outra versão ampliada em 1991).

Em 2008, recebeu o Prêmio Vaultrin Lud Internacional, um dos prêmios mais importantes atribuídos a pesquisadores da Ciência Geográfica. Atualmente, tem sido reconhecido por seus trabalhos no âmbito da Geografia Urbana, apesar de já ter se debruçado em pesquisas e produções científicas em outros campos do conhecimento, a saber: a filosofia e a historiografia. Seu currículo enriquecido pela interdisciplinaridade favoreceu a elaboração do clássico intitulado Filosofía y Ciência em la Geografía Contemporánea: Una Introducción a la Geografia, publicado originalmente em 1981, cujo foco é a epistemologia e consolidação da Geografia enquanto ciência.

Em sua extensa produção científica, especialmente, nos estudos voltados para a análise urbana, destacam-se os três volumes do livro La Morfología de las Ciudades: o primeiro intitulado La Morfologia de las Ciudades: Sociedad, Cultura y Paisaje Urbano; o segundo intitulado La Morfologia de las Ciudades: Aedes Facere: Técnica, Cultura y Clase Social em la Construccíon de Edifícios; e o terceiro intitulado de La Morfologia de las Ciudades: Agentes Urbanos y Mercado Inmobiliario, publicados em 2002, 2005 e 2013, respectivamente. Destacam-se também as obras La Cosmópolis y la Ciudad, publicada em 2003, e Los Ferro-carriles en la Ciudad - Redes Técnicas y Configuración del Espacio Urbano, publicada em 2011.

Nas pesquisas na área da Geografia Urbana, Capel apresenta a importância de analisar a cidade, sem se limitar a sua estrutura física, mas a partir dos seus elementos, dos processos de transformações e de relações sociais, os quais são aspectos constituintes da morfologia urbana. Capel (2002, p. 20) afirma que "la morfologia urbana, el espacio construído, refleja la organización económica, la organización social, las estruturas políticas, los objetos de los grupos sociales dominantes". Desse modo, a construção física da cidade está propícia ao recebimento de uma dinâmica própria, condicionada por fatores econômicos, sociais, políticos e culturais. É nesse espaço urbano que se relacionam os elementos básicos (os planos, as edificações, os usos do solo), configurando-se no tecido urbano como mecanismos capazes de modelar suas estruturas.

Assim, ainda que a forma urbana possa se apresentar de diferentes maneiras nos estudos morfológicos (sejam na forma de estudos historicistas, arquitetônicos, sociológicos 
etc.), descrevemos, neste artigo, alguns elementos fundamentais da análise morfológica, tendo em vista a Geografia como área norteadora, uma vez que ela é uma ciência que estuda a organização espacial e nos permite direcionamentos para a compreensão de toda estrutura urbana, considerando, por exemplo, os diferentes contextos culturais na apreensão das variadas paisagens.

Dessa forma, não enxergamos a morfologia urbana com uma visão restrita e limitada à descrição de formas. Como assevera Capel (2002), esse tipo de estudo serve, singularmente, como ponto de partida e como ponto de chegada para a compreensão da dinâmica urbana. Nesse caso, faz-se necessário considerar a formação dos eventos no desenvolvimento desta análise, os quais são caracterizados pelo autor como estudo da morfogênese (desenvolvimento da sua forma), sendo impossível não considerar tal aspecto para compreensão da configuração atual do espaço que se pretende estudar.

Isto posto, o presente artigo tem como fundamento teórico os três volumes do livro La Morfología de las Ciudades de Horácio Capel. Seguindo essa divisão em volumes, organizamos este artigo em três seções, além da introdução. Na primeira seção, realizamos uma discussão acerca da morfologia urbana e dos elementos que compõem a cidade. Na segunda seção, discutimos como a técnica, a cultura e as dimensões sociais contribuem para a consolidação das formas urbanas. Por fim, na terceira seção, identificamos e discutimos sobre a atuação dos diferentes agentes e atores sociais que produzem e modelam o espaço urbano na contemporaneidade. Assim, ressaltamos que apesar do trabalho crítico do geógrafo Horácio Capel ter sido realizado no contexto turbulento da Europa e do mundo durante a década de 1970, na contemporaneidade os seus apontamentos ainda são importantes para o estudo da Geografia Urbana.

\section{A Morfologia Urbana e os Elementos da Cidade}

A cidade e a sua produção tem sido objeto de pesquisa de diversas ciências, na qual cada área do conhecimento utiliza métodos e procedimentos metodológicos específicos. Entre essas diferentes abordagens tem-se a análise da cidade a partir do estudo da morfologia urbana. Neste enfoque, para compreender as transformações que permeiam o espaço urbano, é necessário contextualizar as suas relações para além das representações das formas urbanas na paisagem.

Assim, entre os diversos pesquisadores e estudiosos do espaço urbano optamos por utilizar, principalmente, a contribuição teórica de Horácio Capel. Além desse autor, trataremos outras referências que também contribuíram para o estudo da morfologia urbana e, consequentemente, o entendimento da análise urbana.

Para o estudo da morfologia urbana, observamos que Capel (2002) destaca alguns elementos, dos quais podemos sublinhar a paisagem. Sob muitos aspectos a paisagem torna-se espelho da forma urbana (das edificações, da existência ou não de vegetação, das praças e áreas de lazer, do parcelamento do solo etc.), evidenciando as suas inter-relações. Para esse autor, a leitura crítica da realidade deve estar assentada de forma direta nos aspectos da renovação da Geografia, sendo necessário considerar diversos agentes, processos e articulações. 
Portanto, considerar a paisagem como um elemento de análise, possibilita, a priori, interligar distintas relações que se cristalizam em nossa sociedade, principalmente quando observamos na paisagem a relação homem versus natureza. Partindo dessa concepção, o estudo da paisagem implica na compreensão das relações do empírico com a maneira em que este, traduzido nas formas espaciais, é apreendido pelo homem, ganhando, assim, uma significação. Segundo Capel (2002, p. 20), "el paisaje urbano constituye uma herencia cultural de gran valor", expressando ações e relações que proporcionam uma investigação sobre a cidade.

Corroborando com isso, Spósito (2004) também busca definir a morfologia urbana para além das aparências da forma, assim a autora afirma que:

o conceito de morfologia urbana não se referiria a uma dada forma urbana (extensão e volume), tal como ela se apresenta configurada espacialmente, mas ao processo de sua gênese e desenvolvimento, segundo os quais podemos explicar essa morfologia e não apenas descrevê-la ou representá-la gráfica ou cartograficamente. Aceitando-se essa perspectiva, a morfologia urbana refere-se não apenas à forma, mas também aos conteúdos que orientam essa forma e são por ela redefinidos continuamente. (SPOSITO, 2004, p. 66)

Para essa autora, realizar uma análise da cidade tomando como referência a sua morfologia, é ir além das aparências ou da mera descrição. Para tanto, torna-se indispensável analisar as dinâmicas e os processos que resultam na atual configuração das formas espaciais da cidade.

Sob este prisma, Lamas (2011) ressalta a importância em analisar a produção da cidade a partir das relações existentes no conjunto urbano que contribuem para definir as áreas. Portanto, o estudo da forma urbana deverá considerar pelo menos três aspectos fundamentais: a) a produção da forma com base em seus aspectos exteriores; b) a divisão do meio urbano em partes e a articulação dessas entre si; e c) os diferentes níveis de produção do espaço urbano. Esses três aspectos correspondem à composição urbana, a qual o autor nomeia como desenho urbano.

Esse desenho urbano é representado também pela paisagem, de forma que a observação desta não se restringe ao que é visível. Carlos (2008) afirma que

a análise da paisagem urbana faz-nos atentar para o fato de que não estamos descrevendo ou montando um quadro, e sim elaborando uma construção cujo objetivo é entender o modo pelo qual ela se produz (...) a partir de relações reais. (2008, p. 44)

Em outras palavras, é crucial compreender os elementos que foram resultantes na sua configuração, como as temporalidades, necessidades, interesses, e os responsáveis pelos processos que a constitui. Contudo, diversas fontes podem ser utilizadas para o estudo da morfologia urbana e auxiliar na leitura da paisagem, como, por exemplo, o uso de imagens de satélite, análise de mapas, fotografias aéreas, leis e normas urbanas e arquivos de propriedade. 
Pela paisagem, podemos identificar as características culturais de um país, de uma cidade, ou de um bairro, tendo em vista sua capacidade de expressar as diferentes configurações de usos do espaço. Desse modo:

as diferenças nesses casos têm a ver com diversas características culturais, como as formas religiosas e as normas sobre o culto, que supõem diferenças na configuração dos espaços sagrados (mesquitas muçulmanas, igrejas cristãs, templos budistas etc.) e seu uso; ou as formas de uso das ruas e espaços públicos em geral, com detalhes importantes na diferenciação do público e do privado. (CAPEL, 2002, p. 68. Tradução livre.)

Há uma necessidade de considerar, na análise da morfologia urbana, a relação entre os elementos básicos que configuram o tecido urbano, bem como os processos que transformam suas estruturas, de modo que, além das dimensões culturais, devem ser consideradas as dimensões econômicas e sociais. Nesse sentido, a existência de uma ampla e diversificada quantidade de elementos compostos na forma urbana podem possibilitar a identificação de diferenças de renda entre indivíduos e entre grupos sociais, constituindo características morfológicas diferenciadas e divididas em setores ricos e pobres nas cidades.

As diferenças espaciais existentes nas cidades, condicionadas, principalmente, pelo desenvolvimento econômico. Essas diferenças são capazes de refletir desigualdades que podem ser expressas na aparência de bairros ou áreas fragmentadas, ocasionando contrastes e divisões sociais, ao ter por um lado, "los paisajes de pobreza (barrio de barrcas, favelas, bidonvilles, centro históricos degradados)", e por outro, "los paisajes de la riqueza (barrio burgueses, áreas de chalets unifamiliares com jardín, country clubs, barrios cerrados, etc.)" (CAPEL, 2002, p. 69).

Por meio da análise da paisagem também é possível apreender a organização econômica do espaço, e, dessa forma, definir um panorama geral sobre qual setor está se reportando. Por exemplo, ao referir-se à paisagem da indústria, paisagem comercial, paisagem do ócio, paisagem dos transportes e/ou das telecomunicações, remete-nos à ideia de espaços constituídos a partir de usos do solo, que possibilitam definir aquele local de acordo com determinado setor econômico e/ou social.

Assim, os usos do solo e as (re)configurações de seus arranjos vão interferir de maneira decisiva na morfologia urbana por meio das atividades que são desenvolvidas em determinados locais. Como ressalta Capel (2002), durante o século XX, foram elaborados diversos mapas representando os diferentes usos dos solos. Em um primeiro instante, elaboraram-se mapas que representavam unidades residenciais e as atividades econômicas que distinguia os usos residenciais, industriais, comerciais, entre outros, e que apresentavam as suas funções segundo o setor correspondente.

Após a Segunda Guerra Mundial, o uso do solo passou a ser alvo de diversos agentes sociais. Um exemplo foi o crescimento significativo da população instalada nas proximidades das indústrias, decorrente do aumento da busca por oportunidades de emprego. Isso, por sua vez, modificou as dinâmicas desses lugares, ocasionando aumento da demanda por transportes públicos e valorização do solo. Portanto, neste cenário, os pa- 
drões de distribuição da utilização do solo foram influenciados pelo sistema econômico e social (CAPEL, 2002).

O crescimento proporcionado pelas mudanças técnicas e econômicas produziu uma expansão do tecido urbano com dimensionamento mundial. Tal expansão acarretou transformações significativas no interior dos espaços urbanos com o deslocamento das atividades comerciais existentes nas áreas centrais para as áreas periféricas, sendo motivo para a realização de estudos comparativos de usos do solo em diferentes cidades. Com efeito, muitos autores passaram a abordar a importância da gestão urbana e promover estudos sobre os agentes urbanos que constroem as cidades, os quais são responsáveis pelo delineamento do tecido urbano, dos usos do solo e, necessariamente, das formas que a cidade adquire (CAPEL, 2002).

Assim, o crescimento das cidades, seja espontâneo ou não, é um aspecto singular para o entendimento da morfologia urbana. Sobre este aspecto, Capel (2002) destaca que alguns autores trabalham com a noção de crescimento "orgânico", considerando-o como natural ou não regulado, fazendo jus ao crescimento espontâneo. Contudo, conforme o autor, não significa que esse crescimento seja totalmente desvinculado de um ordenamento ou uma regra urbanística. Esse tipo de crescimento "se puede reconhecer como la dominante em la mayor parte de las ciudades, y lo há sido durante mucho tempo de grandes urbes como Atena, Roma, Londres o Madrid" (CAPEL, 2002, p. 100).

No entanto, diante da necessidade de trazer um caráter abrangente para os estudos da morfologia urbana, Capel destaca a necessidade de classificar as cidades não apenas pela variável espacial, mas também de levar em consideração seus aspectos culturais, econômicos, sociais e históricos, que podem ser combinados com as características naturais, especialmente as relacionadas ao clima e relevo.

Além disso, destaca-se a clara relação entre a morfologia e o espaço social, pois, como já foi dito, a própria forma urbana é um produto social. Essa forma é produzida por pessoas e por grupos sociais através de processos que podem ser identificados por meio de análises, às quais os agentes e os processos são elementos indispensáveis.

\section{Técnica, Cultura e Dimensões Sociais na Construção da Cidade}

As edificações se apresentam como um dos elementos fundamentais da paisagem urbana, sendo consideradas a parte mais visível da paisagem, porém, ao analisá-las, devemos abordar diferentes dimensões, considerando as técnicas, os aspectos culturais e as relações sociais que estão imbricadas no espaço construído:

Para estudar a edificação, como para outras questões urbanas, é necessária uma abordagem que vá além do quadro disciplinar, pois existem muitas dimensões que se cruzam, e também são muitos os especialistas que têm realizado estudos sobre o assunto. (CAPEL, 2005, p. 13. Tradução livre.)

A análise das edificações abordada por Capel (2005) remete-nos a uma aproximação com diferentes campos do conhecimento, a exemplo da arquitetura, da história, ao 
mesmo tempo em que faz relações com a filosofia, a sociologia e outros áreas do conhecimento, propiciando um olhar multidimensional sem se prender às formas estruturais puras. Para tanto, esse autor considera as diferentes formas de construir, utilizadas desde a antiguidade, as quais são caracterizados pelos materiais disponíveis (a madeira, o barro, a argila, a pedra etc.), até as influências naturais nas características das moradias, baseado nas mudanças estilísticas que inspiraram as edificações entre o século XIX e a contemporaneidade.

A cidade transforma-se em lócus das simultaneidades e das coexistências, uma vez que, como afirma Carlos (2007, p. 55), "a análise da morfologia da cidade revela uma dimensão que não é apenas espacial, mas também temporal, ao mesmo tempo em que aponta uma profunda contradição nos processos de apropriação do espaço pela sociedade". Nesse sentido, compreendendo o espaço urbano como um produto social, que está em constante modificação, se reproduzindo com base nas particularidades e nas técnicas e que, a cada momento, corresponde a uma realidade da sociedade, requer uma análise complexa dos elementos fundamentais envolvidos nesse processo de modificação.

Nesse sentido, é possível identificar que, além das adaptações ambientais, existem outras dimensões na caracterização das edificações. Para Capel (2005), "una de essas dimensiones es la que podemos calificar de forma amplia como socioculturales" (CAPEL, 2005, p. 38). Essa dimensão pode estar presente de diferentes maneiras no espaço construído, seja na presença de elementos religiosos, espaços para realização de cerimonias e de eventos específicos, equipamentos culturais como museus, cinemas, até a disposição das casas, tipo de cômodos, entre outros.

Além dos elementos citados acima, as edificações também se caracterizam na existência das diferentes formas de moradias que estão presentes no ambiente urbano, as quais fazem parte da diversidade social e da forma como a renda se encontra distribuída na sociedade. Em uma sociedade hierarquizada, assim como ocorre no Brasil, é possível haver uma clara distinção entre áreas que correspondem às classes sociais privilegiadas e as áreas formadas por grupos populares marginalizados, ou os segmentos sociais excluídos. Em consonância com isso, Capel (2005) afirma que "sin duda la distinción fundamental es la existence entre las viviendas de los grupos privilegiados, o de rentas altas y las de los pobres (CAPEL, 2005, p. 38).

Um ponto a ser destacado em Capel (2005) é sua percepção sobre a difusão das tipologias construtivas, direcionando um olhar para as moradias burguesas e moradias populares que surgiram no século XIX na Europa. Segundo esse autor, a moradia burguesa constituiu-se isolada com jardins, as casas foram sendo construídas em blocos nas novas expansões centrais da cidade, como também começou a existir uma segregação vertical, pois as antigas moradias (velhos casarões e palácios) ficaram pouco apropriadas para os novos usos da moradia de qualidade. Por isso, muitos casarões foram reformados ou derrubados para dar espaço a novas construções que seguiram um novo modelo, acompanhando os padrões estilísticos da época.

Outro panorama abordado pelo autor diz respeito às características internas das edificações, passando desde o mobiliário até os equipamentos que estão dispostos nas moradias, nas formas ornamentais das portas e janelas, incorporadas por inovações arquitetônicas e influenciadas pela diversidade de estilos e de gostos. Tais características 
representam tipologias diferenciadas de padrões construtivos, as quais são responsáveis por caracterizar uma determinada área da cidade. Com isso, é possível perceber a que grupo social os indivíduos pertencem, e até mesmo relacioná-los ao nível técnico da sociedade em determinado momento. De acordo com Capel (2005):

Ao longo do século XIX, a comunidade habitacional burguesa foi se adaptando aos espaços estilísticos e enriquecendo com novos estilos e com a preocupação com o conforto. Seguindo uma evolução já iniciada no século XVII. (CAPEL, 2005, p. 140. Tradução livre.)

As cidades do século XIX na Espanha, por exemplo, apresentaram intensificações das moradias populares em áreas periféricas, como resultado da forte ocupação dos espaços centrais pela sociedade burguesa e pelo alto custo de acesso à terra. Esse processo foi reflexo de uma fase de crescimento intenso:

com a chegada de um número nunca antes conhecido de imigrantes, expulsos de zonas rurais devido ao crescimento da produtividade agrícola e atraídos pelo emprego na indústria e nos serviços oferecidos nas cidades. Uma dupla Revolução Industrial e Agrária, juntamente com a diminuição da mortalidade, permite a existência de "excedentes" demográficos que são dirigidos às cidades. (CAPEL, 2005, p. 145. Tradução livre.)

Essa mesma realidade pode ser observada no Brasil, porém, tendo um caráter diferente do Europeu pela rapidez de seu crescimento. A maioria dos países europeus tornou-se majoritariamente urbano entre a segunda metade do século XIX e a primeira metade do século XX. Enquanto no Brasil, o intenso crescimento populacional teve seu ápice na década de 1960.

Esse crescimento reforçou suas características de concentração e passou a distribuir elevados contingentes populacionais em um número reduzido de centros urbanos. A rapidez desse processo resultou em uma forte "periferização" nas grandes cidades brasileiras, causando problemas sociais e ambientais, entre os quais se destacam: o desemprego, a favelização, problemas de higiene e insalubridade de moradias. Essa proliferação da moradia precária no Brasil resultou em diversos debates sobre a real necessidade de realizar uma reforma urbana no país.

Contudo, a ideia de reforma urbana no Brasil aparece com uma perspectiva reformista da sociedade, semelhante à realizada nos países capitalistas considerados desenvolvidos, como é o caso da França com a reforma urbanística de Paris, realizada ainda no século XIX. No entanto, Capel (2005) evidencia que a política e as dimensões sociais se consolidam como elementos fundamentais para a análise da forma urbana, podendo estas serem contempladas em diversos períodos históricos.

Tendo as cidades europeias como base de análise, Capel (2005) destaca os impactos ocasionados ao longo da primeira e da segunda Revolução Industrial sobre as cidades e sobre as técnicas de edificações utilizadas. Conforme o autor, o surgimento e disponibilidade de novos materiais tornaram possíveis o surgimento de novas formas de 
construções, e, com isso, também foi possível modificar os ordenamentos que regulam a construção da cidade. De modo que:

por um tempo, aqueles procedentes do passado puderam se adaptar às novas circunstâncias, mas logo ficou claro a necessidade de elaborar outras novas, o que os governos estaduais e municipais se esforçam ordenando e realizando de maneira diferente ao longo do século XIX. (CAPEL, 2005, p. 174. Tradução livre.)

As transformações econômicas e sociais juntamente com as inovações técnicas aplicadas à edificação foram capazes de modificar profundamente a paisagem das cidades contemporâneas. Embora, durante muito tempo tenham utilizado formas construtivas recorrentes do passado, só tardiamente dando espaço às novas possibilidades existentes.

Apesar de pensarmos a cidade como ambiente de vivência, Capel (2005) afirma que a cidade não é só um espaço residencial, ela é, também, um espaço de instituições, de comércios, indústrias e espaços de socialização. Pode-se dizer, dessa forma, que todos esses espaços são para consumo coletivo e constituem equipamentos que compreendem uma finalidade, como produtos ou serviços, e outros correspondem ao funcionamento das estruturas básicas de transporte e comunicação.

Além disso, na análise morfológica da cidade, destacam-se as edificações que têm relações diretas com o Estado, as quais apresentam papel fundamental na transformação da paisagem, a exemplo dos equipamentos de saúde (hospitais, postos, clínicas), de educação (escolas, creches), de cultura (museus, teatros, estádios) e de lazer (praças, parques):

as cidades são as sedes da ciência e da cultura e sempre concentraram os equipamentos educacionais e culturais. Nelas são oferecidos serviços de lazer aos cidadãos, que adquirem importância crescente na sociedade atual. (CAPEL, 2005, p. 391. Tradução livre.)

De modo geral, a análise das edificações possibilita diversas reflexões e rebatimentos acerca das relações sociais, econômicas e políticas de determinado local e determinado período histórico. Dessa forma, faz-se necessário saber quais são os agentes responsáveis pela transformação e ordenamento do espaço urbano, sejam eles públicos ou privados, e se utilizam das diferentes técnicas, funções e instituições para a consolidação do espaço construído, refletindo de maneira direta na morfologia urbana.

\section{Os Agentes Produtores e Modeladores das Cidades}

Capel (2013) apresenta um quadro geral sobre a atuação dos agentes ${ }^{1}$ urbanos e os seus papéis nas transformações das cidades, com o intuito de discutir sobre os fatores que afetam a construção da morfologia urbana. A atenção direcionada por ele diz respeito aos proprietários do solo urbano, aos construtores de edifícios, aos proprietários do comércio enquanto agentes urbanos, e à forma como esses elementos e a própria urbanização se promovem e se lançam no mercado. Destaca-se também a atenção dada 
ao Estado, enquanto regulador e atuante na tomada de decisões; aos agentes financeiros; e ao papel dos técnicos na construção e na comercialização da cidade.

Além da expressão agentes, Capel (2013, p. 17) também utiliza o termo atores, entretanto diferenciando esses atores dos agentes urbanos: para ele os atores "son todos los indivíduos y grupos sociales presentes em la ciudad, que viven y se mueven em ella". Portanto, é possível reconhecer que o papel tanto dos agentes quanto dos atores urbanos apresenta relação próxima com a capacidade que o ser humano tem de tomar decisões. Essas decisões, por sua vez, são responsáveis por refletir nas diversas consequências e fatores espaciais e/ou sociais no interior do espaço urbano.

Capel (2013) ainda apresenta algo que podemos classificar adequadamente como duas subdivisões dos agentes urbanos. A primeira subdivisão diz respeito aos agentes diretos, os quais atuam diretamente na transformação do solo urbano e no seu lançamento no mercado por meio das edificações, ou seja, do espaço construído, são eles: os promotores e construtores imobiliários; os arquitetos; os vendedores; os publicitários etc. A segunda subdivisão corresponde aos agentes indiretos e são aqueles que demandam determinados tipos de edificações para os diversos usos, a exemplo dos empresários que decidem a construção de uma fábrica em um determinado local; dos proprietários que tomam decisões sobre a venda do solo urbano ou se conservam seu uso inicial; e os ligados ao setor financeiro que concedem o capital ou os créditos necessários para que se possa modelar o espaço de acordo com seus interesses.

Na construção das tipologias dos agentes urbanos desenvolvida por Capel, o autor faz uso da abordagem marxista lefebvriana, colocando esses agentes como "nós" das relações sociais no processo de "produção do espaço" (expressão vinculada à formulação de Henri Lefebvre [1984]). Embora esteja se referindo especificamente à realidade europeia, muitos dos agentes identificados por Capel também foram reconhecidos por autores que se dedicaram a analisar a realidade brasileira, ainda que com algumas variações.

Corrêa (1989) na sua simples, mas já clássica, obra, identifica que os agentes capazes de modelar a forma urbana são: os promotores imobiliários; os proprietários fundiários; os proprietários dos meios de produção; o Estado; e os grupos sociais excluídos. É bem verdade que dentro dessas tipologias existem também subdivisões de agentes, que são semelhantes às definições de Capel, principalmente no que se refere aos promotores imobiliários.

Conforme Corrêa (1989), os promotores imobiliários são aqueles que realizam, parcial ou totalmente, as seguintes operações: a) a incorporação; b) o financiamento; c) os estudos técnicos; d) a construção e produção física do imóvel; e) a comercialização ou transformação desses imóveis em capital-dinheiro. Enquanto os proprietários fundiários são aqueles que vão atuar no sentido de obter mais renda fundiária de suas propriedades, isso significa dizer que estão fundamentalmente interessados no valor de troca da terra e não no seu valor de uso.

Os proprietários fundiários também são capazes, de acordo com seus interesses, de exercer pressões junto ao Estado, principalmente na instância municipal, para flexibilização das leis de uso e da ocupação do solo e do zoneamento urbano. Os proprietários dos meios de produção, por sua vez, dizem respeito às empresas industriais que controlam 
as glebas de terras para fins de produção imobiliária. Como dito, essas empresas são essencialmente industriais e sua relação com a terra é temporária.

De acordo com a concepção do autor, o Estado seria aquele que também atua na organização espacial da cidade, diferente de um agente qualquer, o Estado pode ter mais de uma função e "atuar diferentemente como grande indústria, consumidor do espaço e de localizações específicas, proprietário fundiário e promotor imobiliário, sem deixar de ser um regulador do solo urbano e alvo dos chamados movimentos urbanos" (CORRÊA, 1989, p. 24). Enquanto os grupos sociais excluídos seriam aqueles que sofrem diferenças sociais no que se refere ao acesso aos bens e aos serviços públicos produzidos socialmente. Esses grupos têm como possibilidade de moradia as favelas e as ocupações irregulares, normalmente constituídas à revelia dos mecanismos formais do mercado.

Preservadas as particularidades da obra de Corrêa, por ter sido elaborada no final da década de 1980, podemos afirmar que na contemporaneidade são esses mesmos agentes que atuam na transformação do espaço urbano. Ao reler outra obra de Corrêa (2011) podemos afirmar que os agentes são os mesmo atualmente.

No entanto, outros autores ainda preferem utilizar a expressão os sujeitos. No entendimento de Carlos (2011), a noção de produção do espaço urbano nos exige considerar vários níveis de realidade com momentos diferenciados de reprodução da sociedade em sua complexidade. Exige considerar o sujeito da ação como parte integrandos seguintes elementos: do Estado como represente da dominação política; do capital com suas estratégias de reprodução; e dos sujeitos sociais que, em suas necessidades têm o espaço como condição, meio e produto de sua ação. Para o autor, essa concepção permite reconhecer os diferentes níveis que correspondem às práticas socioespaciais que se realizam na produção do espaço urbano com seus passos e descompassos que se estabelecem pelas contradições.

É válido ressaltar que independentemente da concepção adotada, seja na utilização de agentes, atores ou sujeitos, esses elementos são os responsáveis pela materialização dos processos sociais na forma de um ambiente construído. Esses processos ocorrem seja na escala da rede urbana, seja na escala do espaço intraurbano, conduzidos por interesses que são traduzidos, também, nas alianças públicas e privadas. Assim, os agentes urbanos e os processos sociais são indissociáveis, elementos fundamentais da sociedade e de todo seu funcionamento.

Tais alianças funcionam sobre a lógica da financeirização capitalista ligada ao mercado imobiliário. Capel (2013) ressalta que essa lógica é bastante antiga, e seu desenvolvimento ocorreu na idade moderna. No entanto, intensificou-se na metade do século XIX com a possibilidade de organização do sistema de crédito que ampliou o mercado imobiliário. Contudo, somente a partir da década de 1970 esses processos de financiamento se acentuaram nos países capitalistas, a exemplo do Brasil.

Nos últimos anos, o mercado da habitação vem enfrentado transformações importantes, decorrentes da articulação entre o setor público e o privado, sobretudo no financiamento de moradias. Essas moradias variam de acordo com a classe social, o nível de renda e a disponibilidade dos locais onde são ofertadas.

Vale ressaltar que o financiamento habitacional acontece segundo diversos fatores, entre eles, destacam-se: a análise de grupos sociais; a atuação do poder público que po- 
de facilitar ou dificultar o acesso à moradia, principalmente por meio de normatizações de posse e de acesso ao solo; e a atuação do próprio sistema financeiro que permite ou restringe o acesso ao crédito por meio de empréstimos e de subsídios. Dessa forma, Capel (2013) ressalta que:

instituições bancárias e caixas de poupança que concederam auxílio à construção permitiram financiar o intenso crescimento urbano. O desenvolvimento de uma legislação hipotecária para a concessão de créditos com a garantia da propriedade, tornou possível estender o empréstimo a indivíduos e melhorar o acesso à habitação das cidades. (CAPEL, 2013, p. 193. Tradução livre.)

Além de haver um espraiamento das cidades com a possibilidade de maior financiamento habitacional, há de se prever, ao mesmo tempo, o aumento da especulação imobiliária com os processos que se desencadeiam a partir de então. Normalmente, o valor do solo tende a diminuir a partir do centro da cidade para a periferia, isso ocorre de diferentes maneiras e de acordo com as atividades e os usos. Com isso, o preço mais baixo faz com que promotores imobiliários escolham e se apropriem do espaço periurbano para a produção de moradias na garantia de altos lucros.

Nesse sentido, o aumento do número de lançamentos imobiliários e o constante crescimento de empreendimentos tendem a configurar novas dinâmicas urbanas e novos processos imobiliários, demonstrando sua importância na economia local, principalmente no investimento do setor público e privado em novos serviços, fazendo com que locais onde não tinham grande valor passem a ter. Contudo, o mercado imobiliário se constitui como um setor fragmentado, tanto na demanda quanto na oferta, por dividir seu público alvo por estratos de renda (CAPEL, 2013).

Um exemplo prático de alianças público-privadas tendo como base a realidade brasileira é o Programa Minha Casa Minha Vida (PMCMV), criado em 2009 pelo governo federal, cujo intuito é diminuir o déficit habitacional no país. Com a implementação do programa, também podemos encontrar os agentes diretos, envolvendo promotores, técnicos no processo de construção, corretores imobiliários, responsáveis pela comercialização das moradias e os agentes indiretos, sejam eles os donos do solo urbano ou o mercado financeiro enquanto concessor de crédito, entre outros. Com o PMCMV foram criadas facilidades para o acesso à moradia, porém essa produção habitacional também contribuiu para a criação de cidades cada vez mais desiguais, onde se acentua a expansão da malha urbana, e, consequentemente, ocorre uma acelerada transformação na paisagem do espaço periurbano, decorrente do processo de valorização seletiva do espaço e da especulação imobiliária a ela relacionada.

Essa produção imobiliária em larga escala, juntamente com a facilidade de acesso ao crédito impactou na morfologia das cidades brasileiras, sejam elas metropolitanas ou não, na medida em que favoreceu um crescimento urbano em curto prazo, expresso tanto nas expansões horizontais, observadas principalmente nas pequenas cidades, quanto nas expansões verticais, mais notórias nas médias e grandes cidades.

Vale ressaltar o seguinte: para que ocorra essa expansão, além da ação direta dos agentes imobiliários segundos seus interesses, a oferta do solo urbano também deve ser 
considerada como um fator determinante. Segundo Capel (2013), podemos diferenciar a oferta da propriedade e a oferta do solo, sendo a primeira algo mais geral e vinculada à propriedade agrária, enquanto que a oferta do solo tem mais a ver com a propriedade urbana, com o espaço em que se vive e em que se constrói, sendo essencial para o crescimento da cidade.

No entanto, a oferta do solo será afetada por diversos fatores. Em princípio, entende-se que o solo disponível é todo aquele que não está edificado e nem afetado por serviços institucionais (como áreas militares, áreas de planejamento, ordenamento urbanístico, entre eles os derivados do planejamento e áreas de proteção ambiental). Por conseguinte, outros elementos podem afetar a oferta do solo, como os que estão próximos às periferias e acabam influenciando no seu preço (os aterros sanitários, estações elétricas, águas residuais, dejetos de indústrias etc.). Estes últimos afetam negativamente o solo e, consequentemente, fazem baixar seu preço (CAPEL, 2013).

Além disso, com relação ao solo, existem grandes diferenças entre o valor de uso (de uso agrícola, por exemplo, segundo seu rendimento atual e futuro) e o valor de troca, e o preço que está disposto a pagar pela compra do solo (CAPEL, 2013). Desse modo, os proprietários de terras detêm grande poder na permissão das transformações dos usos do solo, as quais afetam diretamente a expansão das cidades. Estes atuam como agentes urbanos que tomam decisões sobre o uso do solo e a venda de suas terras na medida em que:

podem considerar a transformação imediata ou a curto prazo (para construir casas, indústrias, superfícies comerciais, equipamentos diversos...), mas também projetar estratégias conscientes para retê-lo em vista da especulação para conversão futura. (CAPEL, 2013, p. 82. Tradução livre.)

Assim, há de se considerar que, articulados, os proprietários de terra procuram obter a maior renda possível, os construtores o maior lucro, já os financistas os maiores juros possíveis (RODRIGUES, 1989), sendo que a apropriação do espaço urbano estará sujeita a regras de cada um desses capitais em particular. Assim, o espaço urbano vai sendo apropriado de maneira diferenciada pelos diferentes segmentos da sociedade, provocando um acirramento nas disputas entre aqueles que demandam um determinado espaço de moradia, principalmente entre aqueles que se referem às classes de menor renda. Essa apropriação diferenciada também vai rebater diretamente nas materializações sociais no espaço da cidade, ou seja, na sua estrutura social e simbólica que, nas condições ora apresentadas, são desveladas pela morfologia urbana.

Portanto, pelas argumentações apresentadas no decorrer desta seção, é possível postular a importância da análise dos agentes urbanos enquanto agentes definidores da morfologia urbana, envolvendo uma complexidade de relações e de interesses, sejam eles convergentes ou divergentes que aparecem cada vez mais acentuados. Vale destacar que as contribuições apresentadas por Capel (2013) evidenciam a importância de entender o jogo político dos agentes urbanos, bem como as relações políticas, econômicas e sociais em que tais agentes passam a se mesclar, resultando, dessa forma, em uma série de possiblidades para compreender a conformação das cidades na contemporaneidade. 


\section{Considerações Finais}

Os trabalhos desenvolvidos por Horácio Capel são de fundamental importância para a ciência geográfica e, principalmente, para os pesquisadores que se dedicam à análise urbana. O direcionamento de olhares que não se limitam a formas estruturais puras possibilita uma ampla apreensão do espaço construído, refletindo nas mais diversas instâncias sociais que estão interligadas e que, consequentemente, configuram o tecido urbano. Contribuindo com a discussão, autores como Sposito (2004), Carlos (2007; 2008) e Lamas (2011) também apresentam importantes aspectos para a averiguação dos elementos fundamentais que permeiam o espaço urbano, tais como as relações sociais, divisão de classes, desenvolvimentos das atividades econômicas, entre outros.

Considerando a produção da cidade para Capel, observamos que este autor propõe reflexões sobre as dimensões que estão imbricadas na morfologia urbana, como fruto da técnica, da cultura e das dimensões sociais, que se expressam por meio de edificações, estas sendo a parte mais visível da paisagem urbana.

Contudo, a análise urbana não deve se limitar aos aspectos descritivos dos seus elementos morfológicos, assim também a tipologia (das edificações e moradias) deve estar além da sua classificação externa, considerando que o reconhecimento e a identificação das formas existentes são apenas passos iniciais da pesquisa. É nos aspectos sociais, econômicos, políticos, históricos e culturais que a relação dialética apresenta grande contribuição para a delineação da paisagem urbana e social.

Nessa perspectiva, o espaço construído é produto dos agentes sociais que atuam de forma direta e indireta na produção da forma urbana, que agem de acordo com seus interesses e com a sua capacidade de tomar decisões. Entre esses agentes destacam-se a atuação dos proprietários dos meios de produção, dos promotores imobiliários, dos grupos sociais dominantes e dos indivíduos e/ou atores sociais que demandam espaço por moradia, como também considera-se o papel do Estado. Este último, agente fundamental para o suprimento de necessidades e para a realização da vida nas cidades, bem como para reunir recursos, sejam eles políticos ou financeiros. O Estado, portanto, é um agente urbano que atua na produção da cidade e, ao mesmo tempo, é a instância de regulação de conflitos e de gestão de contradições.

Como vimos, apesar de haver preferências pelo uso das expressões "agentes", "atores" ou "sujeitos" entre as análises de Capel (2013); Corrêa (1989; 2011); Carlos (2011), os usos dessas expressões se tratam, na maioria dos casos, dos mesmos envolvidos na produção do espaço. Também se referem àqueles que implantam estratégias variadas em relação aos seus próprios interesses, podendo apresentar conflitos uns com os outros.

A análise urbana, levando em consideração os agentes urbanos, é um assunto de grande importância nos dias atuais, na medida em que permite compreender como a cidade é construída, quais são os fatores essenciais da organização do espaço, da criação da paisagem urbana possibilitando avançar na compreensão e explicação dos seus mecanismos e lógicas.

Contudo, embora Capel e demais autores apresentem um rico caminho para compreender as transformações que ocorrem no espaço urbano, estabelecendo uma relação 
do estudo da forma urbana com os processos que atuam nessa dinâmica temporal e espacial, nos surgem os seguintes questionamentos: seria mesmo possível, com base nos mais variados objetivos e focos de observação desenvolver uma tipologia "geral" dos agentes urbanos? Todos os proprietários industriais atuariam de forma única independente da realidade em que se localizam? Os atores, os sujeitos ou os grupos sociais excluídos não seriam muito abrangentes, tendo em vista os diferentes segmentos da sociedade e cada maneira específica de demandar e de intervir no espaço urbano?

Acreditamos, portanto, que a análise urbana deve levar em consideração cada realidade empírica, o que possibilitará uma melhor apreensão da produção desses espaços, pois juntamente com ele a quantidade e a qualidade - de ações, das estratégias, dos conflitos etc. - dos agentes urbanos muda. Dessa forma, a análise a ser empregada deverá adotar estratégias como forma de melhor perceber e avançar no sentido de identificar os agentes urbanos que compreendem conteúdos e atuações distintas, sendo resultado de fatores políticos, econômicos, sociais e culturais que são materializados na sociedade em sua totalidade.

\section{Referências Bibliográficas}

CAPEL, H. La morfologia de las ciudades. Vol. I: Sociedad, cultura y paisage urbano. Espanha, Barcelona: Ediciones del Serbal, 2002.

. La morfologia de las ciudades. Vol. II: Aedes facere: técnica, cultura y clase social em la construccíon de edifícios. Espanha: Ediciones del Serbal, 2005.

. La morfologia de las ciudades. Vol. III: Agentes urbanos y mercado inmobiliario. Espanha, Barcelona: Ediciones del Serbal, 2013.

CARLOS, A. F. A. O espaço urbano: novos escritos sobre a cidade. São Paulo: Labur Edições, 2007.

A (re)produção do espaço urbano. 1. ed. 1. reimpr. São Paulo: Edusp, 2008.

. Da "organização" à "produção" do espaço no movimento do pensamento geográfico. In: CARLOS, A. F. A.; SOUZA, M. L.; SPOSITO, M. E. B. (orgs.). A produção do espaço urbano: agentes e processos, escalas e desafios. São Paulo: Contexto, 2011.

Sobre agentes sociais, escala e produção do espaço: um texto para discussão. In: CARLOS, A. F. A.; SOUZA, M. L.; SPOSITO, M. E. B. (orgs.). A produção do espaço urbano: agentes e processos, escalas e desafios. São Paulo: Contexto, 2011.

CORRÊA, R. L. O espaço urbano. São Paulo: Editora Ática, 1989.

LAMAS, J. M. R. G. Morfologia e desenho da cidade. 6. ed. Lisboa: Fundação Calouste Gulbenkian, Ministério da Ciência e do Ensino Superior, 2011. 
Denis Rodrigues Dantas, Élida Thalita Silva de Carvalho e Julia Diniz de Oliveira

LEFEBVRE. H. La producción del espacio. Barcelona: Anthropos, 1984.

RODRIGUES, A. M. Moradia nas cidades brasileiras. São Paulo: Contexto, 1989.

SPOSITO, M. E. B. O chão em pedaços: urbanização, economia e cidades no Estado de São Paulo. Tese (Livre Docência) - Universidade Estadual Paulista, Faculdade de Ciências Tecnologia. Presidente Prudente: [s.n], 2004.

Recebido em: 21/06/2018 Aceito em: 06/01/2019

1 Neste trabalho, o termo agentes se refere aos sujeitos responsáveis por modelar/transformar o espaço construído, bem como outras funções diretas e indiretas que podem aparecer no papel dos agentes urbanos. 